\title{
Reviews
}

\section{IAN BODEN}

Executive Editor and Training

Coordinator of The National (PNG)

\section{An unusual, insightful Pacific book}

The Pacific Journalist: A Practical Guide, edited by David Robie. Suva: University of the South Pacific Journalism Programme/USP Book Centre, and South Pacific Books (NZ), 2001, 372 pp. ISBN: 982-01-0385-1.

VERY rarely does a book appear in the South Pacific that is generated within the region and intended for those working here. Even more unusually does such a book address itself to the needs of Pacific Islands journalism, to the rights of the public to be informed, and to the responsibilities and obligations of journalists.

Add to that an attempt to cover not only the print media, but to address television, radio and on-line news dissemination and you have a book with the potential to become a landmark publication.

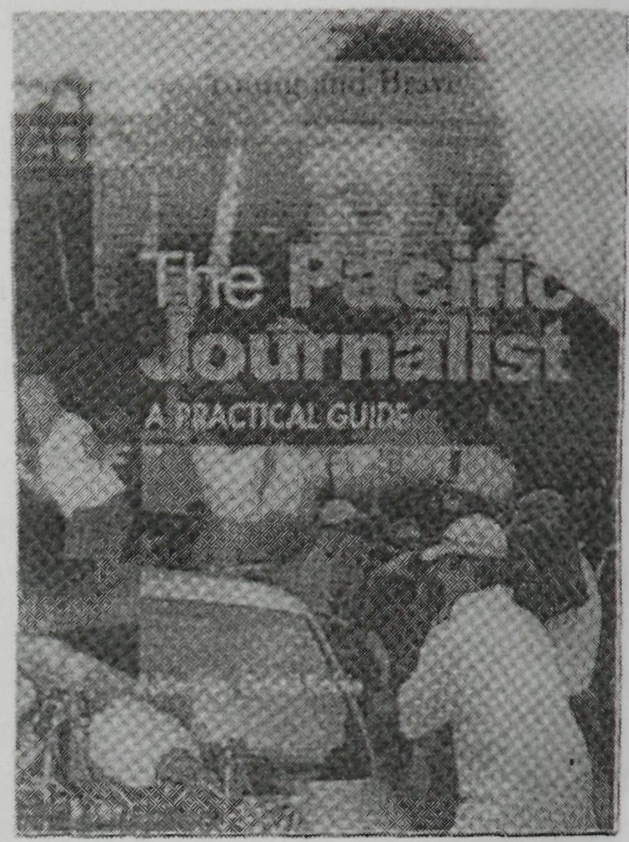

The Pacific Journalist, edited by David Robie and jointly published by the Journalism Programme at the University of the South Pacific (USP) and the USP Book Centre comes close to fulfilling that potential. It is an interesting concept, this combined how-10be-a-good-journalist manual and commentary on Pacific issues.

Robie, who by this stage of his career has amassed a great deal of experience and knowledge of this region, writes cleanly and with a sense of direction, giving easily accessible and readily absorbed information that 
many younger journalists will find most welcome.

Historically journalism in the region has perhaps flowered best in Papua New Guinea, although Fiji through USP - and one suspects with strong prodding from Robie - is producing qualified journalists in increasing numbers.

The editor of The Pacific Journalist spent five years in PNG as the head of a high-profile journalism departinent at the University of PNG. That course produced a number of distinguished journalists, people of the calibre of Kevin Pamba, a regular contributor to The National, now lecturing at PNG's other journalism school within Divine Word University at Madang.

Robie is now the University of South Pacific's journalism coordinator. The Pacific Journalist sets itself modest aims. "I hope this book will contribute to raising professional and ethical standards among journalists around the region," the editor says at the end of his acknowledgements.

One of the admirable qualities of this book is the emphasis on student journalists, their opinions, their reasons for wanting to join the profession, and their hopes for themselves and their countries.

The first section of 'The Pacific Journalist' concerns itself with news values, but begins by posing the ques- tion "why do Pacific Islanders want to become journalists?" The answers to that question, quoting students from three Pacific countries, make an excellent springboard for what follows, which takes the reader from the basic consideration of journalism - the functions of the media, the qualities needed to become a journalist through to questions all journalists should ask themselves when they write.

Is it significant? Does it have human interest? Is it topical and relevant'? Robie's approach is sensible. The text is interspersed with quotes underlining the points he seeks to make, and illustrations, generally of reproduced news pages give both good examples of appropriate and even courageous writing and a fair sprinkling of clangers, some of which have led to defamation cases against writers and publishers alike.

And that is the concern of the second section of the book - media law and ethics. There is an informative chapter on the legal systems of the Pacific as they effect journalists, by Philip Cass and an article on corporate pressure and ethics by Mala Jagmohan, a former editor of Fiji's Sunday Times, which will generate a few wry smiles among those writing in a region notorious for the heavy hand of commercial interests.

A useful chapter on reporting and the courts by Robie follows; and then 
a fascinating article on political reporting and editorial balance by Jale Moala, who is one of the region's most distinguished journalists, and former editor of The Fiji Times, the Daily Post, the Pacific Islands Monthly, and Islands Business.

There is a section devoted to the print media, with strong articles on feature writing, layout and sub-editing, followed by another for the broadcast media. That section includes a chapter by Pat Craddock - "Radio journalism and the interview" - who like Robie works at USP [he has recently moved to Mozambique where he also trains broadcasters], and who has had experience in Kiribati, Tonga, the Solomons, as well as PNG, where I recall working with him at our own NBC some 20 years ago.

Television reporting is covered by Ingrid Leary, who produced the remarkable Maire, the documentary about living with AIDS in the Pacific. The last two sections deal with online reporting, including web publishing and editing, and there is an excellent finale "Issues in the Media". This forms an invaluable postscript to the book with four outstanding articles.

Samantha Magick is the political and communications officer with environmental group Greenpeace, and she is the former news editor of Communications Fiji Ltd. Magick writes on the relationship between the $\mathrm{Pa}$ - cific media and non-governmental organisations, an issue of major concern to many journalists in this region. Anna Shadbolt contributes a valuable chapter on trauma as it affects journalists covering disasters, military confrontations and unexpected deaths. Ms Shadbolt is a psychologist who was a lecturer at USP.

The third article comes from Trevor Cullen, long known for his advocacy of journalism that addresses AIDS in the Pacific, and a former lecturer at Divine Word University in Madang. This is a trumpet call to $\mathrm{Pa}$ cific journalists to wake up to what is no longer a threat, but has become a sad fact of life - the Pacific and especially PNG are now among the world's growth areas for the disease.

Cullen makes many valid points in his article. Let's stop being politically correct, he says, because the issue is bigger than that - but let's observe the sensitivities of covering AIDS. Cullen emphasises the human face of the disease and the need for Pacific journalists to be proactive rather than reactive to coverage of AIDS in the community.

The last article in The Pacific Journalist is contributed by the ABC's regional journalist Richard Dinnen, who is based in Port Moresby. Dinnen's article "Outside looking in - foreign correspondents" is alone worth the price of this book. He gives 
a rare insight into the thinking of a scrupulous and ethical journalist working in an environment and covering issues as remote from his own culture as the Earth is from Pluto.

Dinnen writes with precision and a fine understanding of the joys of using the English language. In an article that covers 33 pages, he begins by pointing out the ironies of fly-in, flyout foreign correspondents in the $\mathrm{Pa}$ cific, those "who don't know a vatu from a ratu, an atoll from an Ayatollah, or Polynesia from Indonesia".

There are significant sections that broadly cover decision-making. He seeks to establish the bases for determining what Pacific stories are newsworthy, and in what context, writes of covering conflict and regional relationships and includes an excellent section on being a stringer, which should be required reading for every Pacific island freelancer.

All of the chapters in The Pacific Journalist have resource and further reading lists, there is an excellent glossary and a chronology of Pacific events, legal terms and their meanings and a detailed index.

The book is clearly the initiative of David Robie, and the sub-title, "A Practical Guide" is the best brief description of the book's value to Pacific journalists.

It is hard to imagine any Pacific newsroom twelve months hence with- out a much thumbed copy of The Pacific: Journalist, simply because it brings together under one cover so much information that is of value to journalists working in the region.

Robie and those who have contributed the excellent articles deserve commendation for this publication, which I have no hesitation in recommending to students and young journalists, those who would like to be journalists, and grizzled old hacks like myself who sometimes need to be reminded of the basics of our profession. 